\title{
Benthic Microbial Diversity and Connectivity in Potential Polymetallic Nodule Mining Areas
}

BATUHAN CAGRI YAPAN ${ }^{1}$, MASSIMILIANO MOLARI ${ }^{1}$, JULIA M. OTTE ${ }^{2}$, FELIX JANSSEN ${ }^{3}$, FRANK WENZHÖFER ${ }^{4}$, MATTHIAS HAECKEL ${ }^{5}$ AND ANTJE BOETIUS $^{3}$

${ }^{1}$ Max Planck Institute for Marine Microbiology

${ }^{2}$ Alfred Wegener Institute for Polar and Marine Research in the Helmholtz Association

${ }^{3}$ Alfred Wegener Institute Helmholtz Centre for Polar and Marine Research

${ }^{4}$ University of Southern Denmark

${ }^{5}$ GEOMAR Helmholtz Centre for Ocean Research Kiel

Presenting Author: byapan@mpi-bremen.de

Polymetallic nodule rich abyssal plains are potential mining areas. Despite the vast area covered by abyssal plains and their important role in element cycles, there is limited knowledge on microbial communities thriving in these regions, and their role in Earth's ecosystem. Deep sea mining might create a risk for those unexplored communities. Elucidation of microbial diversity and the description of the connectivity between microbial communities have vital importance for understanding and mitigating potential negative impacts of deep-sea mining activities. Our study aims to investigate bacterial and archaeal diversity in surface sediments, nodules and bottom water collected in BGR and GSR contract areas in the eastern part of the Clarion Clipperton Fracture Zone (CCZ), separated by approx. $1000 \mathrm{~km}$. In each contract area samples were collected in two areas across a spatial scale from hundreds of meters to 10 $\mathrm{km}$. To investigate pattern under different trophic conditions (i.e. sedimentation rates) and at ocean basin scale, the microbial diversity of nodules deposit in the Peru Basin [1], located more than $5000 \mathrm{~km}$ away from $\mathrm{CCZ}$, were included in the analysis of alpha and beta-diversity. In this presentation, results from $16 \mathrm{~S}$ rRNA amplicon analyses of bacterial and archaeal communities will be presented. Preliminary results indicate a significant clustering of the sediment microbial communities by the geographic distance, and differences in diversity patterns in different areas. Observed differences in microbial community composition among nodules, sediments, and water will be discussed further within the perspective of geographic distance and comprehensive biogeochemical data (e.g. carbon content, Chloroplast Pigment Equivalent levels). Findings of this study have an important contribution to knowledge on microbial diversity and connectivity of Pacific Ocean abyssal plains. Understanding the factors shaping structure of microbial assemblages would be useful to develop policies for mitigating potential large-scale negative impacts of deep-sea mining, and restoration of these habitats.

[1]Vonnahme et al. (2020), Sci. Adv. 6, DOI: 10.1126/sciadv.aaz5922 